EPiC Series in Education Science
Volume 1, 2017, Pages 19-26
$\begin{gathered}\text { AUBEA 2017: Australasian Universities Build- } \\ \text { ing Education Association Conference 2017 }\end{gathered}$

\title{
DETERMINANTS OF ACADEMIC QUALITY DISPARITY AMONG CONSTRUCTION POST-GRADUATE STUDENTS IN GHANA.
}

\author{
De-Graft Owusu-Manu 1, 2*, Daniel Yamoah Agyemang 2, \\ 2 †and Michael Addy 3, $2^{\ddagger}$ \\ ${ }^{1,3}$ Lecturers \\ ${ }^{2}$ M.Sc. Candidate \\ ${ }^{2}$ Kwame Nkrumah University of Science and Technology, Ghana. \\ 1 d.owusumanu@gmail.com, 2 junidan20@gmail.com , \\ ${ }^{3}$ mljaddy@yahoo.co.uk
}

\begin{abstract}
In this global era and insurgency of technology, education is seen as a first pace for every human activity. However, there seem to exist various determinants which results in difference in academic performance among students. This study was designed to examine the attribution factors affecting academic performance of construction post-graduate students of KNUST-Kumasi. Based on extensive literature review the attribution factors could be grouped into five main components. Presented are results from statistical analyses of 49 questionnaire survey responses from construction post graduate students of KNUST-Kumasi. The results validated all the 15 attribution factors of academic performance used for the survey. Personal study periods, the role played by lecturers and financial status are identified as the most attributed factor affecting academic performance of tertiary students. To analyse the data, non-parametric statistical testing using descriptive statistics, mean score index and Relative Importance Index (RII) were used through appropriate statistical package. The findings of this paper could help policy makers especially those in the Quality Assurance unit, the Central Academic office and the Ministry of Education on what policies and strategies can be employed to improve academic performance in institutions of higher learning as well as students, parents and teachers to guide them properly and as per their abilities. For further studies, it is recommended that more predictive variables be added so as to ascertain more significant predictors of academic performance of tertiary students.
\end{abstract}

\footnotetext{
* Principal Project Supervisor

${ }^{\dagger}$ Created the draft of the paper

${ }^{\ddagger}$ Associate Supervisor
} 


\section{Introduction}

Education plays a pulsating role in the improvement of human capital and interconnected with an individual's well-being and opportunities for better living (Battle and Lewis, 2002). An evenhanded education system can recompense the effect of comprehensive social and economic inequalities. Ali et al. (2009) confers that the students' performance (academic achievement) plays an important role in producing the best quality graduates who will become great leader and manpower for the country thus responsible for the country's economic and social development. Student academic performance measurements are a challenging aspect of academic literature and as such are influenced by social, psychological, economic, environmental and personal factors. Student's academic performance is measured through several ways like Cumulative Grade Point Average (CGPA), Cumulative Weighted Average (CWA) and their test result. According to Hijazi and Naqvi (2006), student performance is measured through the result of particular subject or the previous year result.

Quality in education is viewed as a persuasive factor in instigating plans for bridging the poverty gaps between the developing and the developed worlds. Despite the fact that the concept of quality and its priority pointers may be at variance from nation to nation, it is universally reflected as a determining influence in facilitating the implementation of education for all initiatives (World Bank Independent Evaluation Group, 2006). Unfortunately, defining and measuring the quality of education is not a simple issue and the intricacy of this process increases due to the changing tenets of quality characteristics associated with the different stakeholders' viewpoint (Blevins, 2009; Parri, 2006).

The objective of this research paper is to explore the important factors that affect the academic performance of construction post-graduate students. Extensive literature shows a plethora of study on this area. Construction post-graduate students of Kwame Nkrumah University of Science and Technology (KNUST) are taken as population and focuses on the result of the student performance and their achievements in the academic year. The study therefore addresses all the pressing issues and concerns in the Ghanaian Tertiary Sector of Education. This paper therefore positions itself in a better way to enable the researcher make recommendations to KNUST policy makers especially those in the Quality Assurance unit, the Central Academic office and the Ministry of Education on what policies and strategies can be adopted to improve academic performance in institutions of higher learning. Work in this area has the potential to provide important suggestions to improve standard and quality of education and performance of student that is by no means deniable in a developing country like Ghana.

\section{Literature Review: Factors that Influence Academic Performance}

Academic performance is defined or regarded as participants' examination grades (CWA or CGPA) at the end of a particular semester or programme according to this study. It could also be seen as the level of performance in a particular field of study. According to Egbule (2004), higher scores indicate better academic performance. Some other researchers used test results or previous year result since they were studying performance for the specific subject or year (Hijazi and Naqvi, 2006). The following subsections discuss these determinants.

\subsection{Teachers, Learning Facilities and Learning Environment}

This literature discusses two types of factors that affect the students' academic performance. These are internal and external classroom factors. Students spend most of their time in classrooms 
and lecture theatres, thus teachers represent the aspect of school quality that is most closely linked to gains in students' academic achievement (Rivkin et al., 1998). The academic environment is the effective variable for students (Kirmani and Siddiquah, 2008).

\subsection{Parent's Education Level and Occupation}

As sole parent families on average have lower levels of income, and are thus headed by parents with lower educational attainment. These families are less likely to be in the labour force and as such children from these families are likely to have lower educational performance (Rich, 2000). Owens (1999) in her research, studied the relationship between parent's educational attainment to their wards academic achievement and she concluded that the higher the parent's educational achievement, the higher the academic achievement of their wards.

\subsection{Peer Influence}

Peer pressure refers to the influence exerted by a peer group in encouraging a person to change his/her attitudes, values in order to conform to group norms (Kirk, 2000). Given that adolescents spend twice as much time with peers as compared to parents or other adults is reason enough to study the influence or pressures that peers place on each other especially with regards to academic performance (Ryan, 2000).

\subsection{Gender}

Gender relates to the difference in sex (that is, either male or female) and how this quality affects their dispositions and perception toward life and academic activities (Okoh, 2007). Reviews of the evidence suggest that boys suffer an educational disadvantage relative to girls, especially in terms of performance in literacy (Buckingham, 1999; 2000b).

\subsection{Age Difference}

Cognitive development and maturity (which are associated with age) are necessary for a worthwhile performance of students. Age of the individual, as it increases, usually affects the various developmental changes. It also affects every area of human performance (Ukueze, 2007). Research that has investigated the effects of age on student performance has generally found that mature-age students receive higher grades in tertiary education settings (Hoskins et al., 1997).

\subsection{Socio-Economic Status}

Social economic status is most frequently determined by merging parents' educational level, occupational status and income level (Jeynes, 2002). Hansen and Mastekaasa (2006), argue that from cultural capital theory one could expect students from families who are closest to the academic culture to have greatest success. It is believed that low social economic status negatively affects academic success because it prevents access to vital resources and creates additional stress at home (Eamon, 2005). 


\subsection{Income}

Escarce (2003) adds that due to residential stratification and segregation, low-income students usually attend schools with lower funding levels, have reduced achievement motivation and much higher risk of educational failure. When compared with their more affluent counterparts, low income adolescents receive lower grades, earn lower scores on standardized test and are much more likely to drop out of school. Considine and Zappala (2002) found that children from families with low income are more likely to exhibit the following patterns in terms of educational outcomes; lower levels of literacy, lower retention rates, higher levels of problematic school behavior, more likely to have difficulties with their studies and display negative attitudes to school.

\begin{tabular}{|c|c|}
\hline ATTRIBUTION FACTORS. & SOURCE \\
\hline ACADEMIC FACTORS & \\
\hline Learning Facilities & Karemera (2003), Mujtaba and Mujtaba (2004) \\
\hline Learning Environment & Kirmani \& Siddiquah (2008), Crosnoe et al., (2004) \\
\hline Teachers/Lecturers & $\begin{array}{l}\text { Killen et al. (2003), Bali \& Alverez (2003), Oloyede } \\
(2007)\end{array}$ \\
\hline STUDENT FACTORS & \\
\hline Personal study periods & Steenkamp et al. (2009) \\
\hline FAMILY FACTORS & \\
\hline Parent's Education Level & Rich (2000), Hussain (2006), Owens (1999), \\
\hline Parent's Occupation & Raychaudhury et al. (2010) \\
\hline PEER FACTORS & \\
\hline Influence from Peers & $\begin{array}{l}\text { Kirk (2000), Wilkinson \& Fung (2002), Santor et } \\
\text { al. (2000) }\end{array}$ \\
\hline SOCIAL FACTORS & \\
\hline Gender & Buadi (2000), Buckingham $(1999 ; 2000 b)$ \\
\hline Age Difference & Ukueze (2007), Hoskins et al. (1997), \\
\hline Socio-Economic Status & Jeynes (2002), Mastekaasa (2006) \\
\hline Ethnicity & Portes \& MacLeod (1996), Marks et al. (2000) \\
\hline Income (financial status) & Escarce (2003), Sentamu (2003), Egbule (2004) \\
\hline Language & Eamon (2005), Graetz (1995) \\
\hline
\end{tabular}

Table 1: Attribution Factors influencing Academic Performance

\section{Research Methodology}

This section discusses the sample selection procedure, variables selection, the model used for the research and the statistical techniques.

This research adopts a quantitative strategy. The extent of existence for all variables in the research area was measured on a five-point likert scale ranging from, (A)-strongly disagree to (E)Strongly Agree. The study adopted the use of investigative design with a well-structured questionnaire administered by the researcher. Primary data was sourced from post-graduate construction students in the form of field survey (questionnaires). Population as defined by Cooper 
et al. (2001) is described to be the composition of all individuals of whom measurement is taken. Studied population included post-graduate construction students involving young and matured students specifically of KNUST-Kumasi. For this study, due to the size of the total population thus 52 construction post-graduate students, census study was adopted. Fifty-two (52) questionnaires were distributed. Forty-nine (49) responses could be deemed representative indicating a high response rate of $93 \%$ as a result of persistent follow ups to retrieving the questionnaires. Moreover, this satisfies the recommendation of many researchers (Ott and Longnecker, 2001) that for any group, a minimum sample size of 30 is deemed representative.

For the purpose of this study the main sampling technique employed was the purposive sampling technique that is a given unit with knowledge on the research were selected. Non-parametric statistical testing using descriptive statistics, mean score index and Relative Importance Index (RII) were used through appropriate statistical package.

\section{Results}

Findings of the study are discussed below:

\subsection{Data Analysis and Discussion}

This section analyses the data collected for the study thus descriptive analysis of attribution factors of academic quality.

\subsection{Descriptive Analysis}

Descriptive statistics represents the calculated means, standard deviations and RII for the fifteen (15) dependent variables and independent variable, student performance.

Mean of Personal study periods, Teachers/Lecturers, Income, Learning Facility, Learning Environment, Influence from Peers, Marital Status, Age Difference, Socio-Economic Status, Parent's Education, Place of residence, Parent's Occupation, Language, Gender and Ethnicity were 4.1224, $4.0000,3.8163,3.7347,3.7143,3.551,3.2653,3.1224,3.0612,2.6939,2.6327,2.6122,2.4898$, 2.2653 and 1.8571 respectively, as shown in Table 2: 


\begin{tabular}{|c|c|c|c|c|c|c|c|}
\hline \multirow[b]{2}{*}{ DETERMINANTS } & \multirow[b]{2}{*}{$N$} & \multirow[b]{2}{*}{ Sum } & \multirow[b]{2}{*}{$R I I$} & \multirow[b]{2}{*}{ Ranking } & \multicolumn{2}{|c|}{ Mean } & \multirow{2}{*}{$\begin{array}{c}\text { Std. } \\
\text { Deviation }\end{array}$} \\
\hline & & & & & Statistic & $\begin{array}{l}\text { Std. } \\
\text { Error }\end{array}$ & \\
\hline Personal study periods & 49 & 202 & 82 & $1^{\text {st }}$ & 4.1224 & 0.12921 & 0.90445 \\
\hline Teachers/Lecturers & 49 & 196 & 80 & $2^{\text {nd }}$ & 4.0000 & 0.13041 & 0.91287 \\
\hline $\begin{array}{l}\text { Income (financial } \\
\text { status) }\end{array}$ & 49 & 187 & 76 & $3^{\text {rd }}$ & 3.8163 & 0.1534 & 1.07381 \\
\hline Learning Facility & 49 & 183 & 75 & $4^{\text {th }}$ & 3.7347 & 0.15089 & 1.05624 \\
\hline $\begin{array}{l}\text { Learning } \\
\text { Environment }\end{array}$ & 49 & 182 & 74 & $5^{\text {th }}$ & 3.7143 & 0.14286 & 1.00000 \\
\hline Influence from Peers & 49 & 174 & 71 & $6^{\text {th }}$ & 3.5510 & 0.14004 & 0.98025 \\
\hline Marital Status & 49 & 160 & 65 & $7^{\text {th }}$ & 3.2653 & 0.13608 & 0.95253 \\
\hline Age Difference & 49 & 153 & 62 & $8^{\text {th }}$ & 3.1224 & 0.16911 & 1.18379 \\
\hline Socio-Economic Status & 49 & 150 & 61 & $9^{\text {th }}$ & 3.0612 & 0.14985 & 1.04897 \\
\hline Parent's Education & 49 & 132 & 54 & $10^{\text {th }}$ & 2.6939 & 0.16289 & 1.14025 \\
\hline Place of residence & 49 & 129 & 53 & $11^{\text {th }}$ & 2.6327 & 0.18139 & 1.26974 \\
\hline Parent's Occupation & 49 & 128 & 52 & $12^{\text {th }}$ & 2.6122 & 0.14816 & 1.03715 \\
\hline Language & 49 & 122 & 50 & $13^{\text {th }}$ & 2.4898 & 0.16783 & 1.17478 \\
\hline Gender & 49 & 111 & 45 & $14^{\text {th }}$ & 2.2653 & 0.19944 & 1.39606 \\
\hline Ethnicity & 49 & 91 & 37 & $15^{\text {th }}$ & 1.8571 & 0.14869 & 1.04083 \\
\hline
\end{tabular}

Table 2: Descriptive Statistics of Attribution factors of Academic Quality

\subsection{Discussion}

After a survey was carried out by questionnaire, it was deduced that almost all of the attribution factors were surprisingly determinants of academic quality within the Tertiary Level of Education with twelve (12) out of the fifteen (15) determinants attaining a high RII above $50 \%$ and three (3) attaining RII below $50 \%$.

The results showed that the most attributed factor with respect to academic performance of Postgraduate construction students is Personal Study Period. This is the personal time respondents had to study. Personal Study Periods had the highest RII of 82. This finding is somewhat consistent with Steenkamp et al. (2009) study which found that regular attendance at lecture complemented by study effort and long hours spent studying accounted for student's success.

The second most important attribution factor of academic quality is the role played by Lecturers. Role of Lecturers had an RII ranking of 80 with its mean value 4.00 which is also skewed to 4 . This finding is also consistent with Bali and Alverez (2003) study which found that students who attend schools with a higher number of teachers with full credential tend to perform better and vice versa.

Financial status followed as it was ranked third with an RII of 76. In this study, financial status and income are used interchangeably. After the analysis the results showed that, to a large extent, construction post-graduate students agree to the statistics that financial status is also another major factor affecting academic performance since its mean value 3.82 is closely lopsided to 4 which stands for "more important" on the Likert scale. According to Escarce (2003) family income, has a profound influence on the educational opportunities available to adolescents and on their chances of educational success. 
The fourth attribution factor of academic quality is learning facility thus with an RII value of 75 . Karemera (2003) found that students' performance is significantly correlated with satisfaction with academic environment and the facilities of library, computer lab and etc. in the institution.

Learning Environment was ranked 5th according to table 1 shown above. Learning environment had an RII score of 74 with a mean value of 3.71 .

The 6th attribution factor was peer influence which had an RII of 71 with its mean value 3.55 which is skewed to 4. This is consistent with Wilkinson and Fung (2002) study as they concluded that; by grouping students in heterogeneous learning ability (low ability students grouped with high ability students) will show an improvement in learning process and outcomes.

Similarly, Marital Status, Age Difference, Socio-Economic Status, Parent's Education, Place of residence, Parent's Occupation were ranked 7th, 8th, 9th, 10th, 11th, and 12th respectively. They all had an RII score of $65,62,61,54,53$ and 52 respectively. Interestingly, all the mean values are skewed towards 3 on the Likert scale meaning all these factors of academic performance are of essence.

\section{CONCLUSIONS}

The main objective of this paper was to identify the attribution factors of academic quality disparity between young and matured construction post-graduate students. This objective was achieved by asking the respondents on fifteen (15) determinants of academic performance in the tertiary level of education after a thorough literature enquiry. The factors were ranked based on the responses received using the Relative Importance Index tool according to their order of importance as well as mean score ranking.

\subsection{Suggestions and Recommendations}

Based on the study findings, the researcher derived the following recommendations:

- The KNUST admissions committee should not only focus on academic performance of applicants but also on the financial status. The university could also devise means of paying special attention to students from low social economic backgrounds. For e.g. the university could improve the student support system such that students from low socio-economic backgrounds are identified and assisted with financial aid or even a student loan scheme could be developed.

- The student performance could be improved if the administration of the University provides proper learning facilities for the post-graduate students and also improve the learning environment of the University. Adequate educational resources such as well-equipped libraries, laboratories, lecture rooms etc. should be made available for both students and lecturers. This will make teaching convenient for the lecturers and provide good learning environment for the students.

- Based on the findings from the study, it is recommended that for further studies, more predictive variables be added so as to ascertain more significant predictors of academic performance of students. 


\section{References}

Carlisle, D. (2010, April). graphicx: Enhanced support for graphics. Retrieved from http://www.ctan.org/tex-archive/ help/Catalogue/entries/graphicx.html

Voronkov, A. (2004). EasyChair conference system. Retrieved from easychair.org

Voronkov, A. (2014). Keynote talk: EasyChair. In Proceeedings of the 29th ACM/IEEE International Conference on Automated Software Engineering (pp. 3-4). ACM. Retrieved from http://dl.acm.org/citation.cfm?id=2643085\&dl=ACM\&coll=DL

Voronkov, A., \& Hoder, K. (n.d.). Templates. Retrieved from Templates for proceedings: https://easychair.org/proceedings/template.cgi?a=12732737

Wikipedia. (n.d.). EasyChair. Retrieved from Wikipedia: https://en.wikipedia.org/wiki/EasyChair 